\title{
Gender-specific development of nonverbal behaviours and mild depression in adolescence
}

\author{
Yolanda van Beek, Marlies S. M. van Dolderen, and Judith J. S. Demon Dubas \\ Developmental Psychology, Utrecht University, The Netherlands
}

\begin{abstract}
Background: Individual differences in depressive symptoms have been linked with social skill deficits in adults and children, yet empirical studies on adolescents are lacking. The present research examines age and gender differences in nonverbal behaviour between mildly depressed and nondepressed (pre-) adolescents during conversations with an adult (study 1) and a same-aged peer (study 2). Both studies also examine whether conversation partners respond differently to mildly depressed versus nondepressed (pre)adolescents. Methods: Study 1 reports on observations of conversations of 9-15-yearold children $(n=122)$ with a female adult partner. Study 2 reports findings of observations of 12-17year-old adolescents $(n=154)$ in conversation with same-age, same-sex peers. Results: Both studies show gender and/or age effects in gazing, smiling and backchannel behaviours that indicate that as adolescents mature they increasingly behave according to gender-specific display rules. While talking to an adult, depressed (pre-)adolescents and the adult partner differed in backchannel behaviours. While talking to peers, only depressed adolescent girls showed less gazing towards the partner during listening. Moreover, adolescents smiled less often towards depressed than nondepressed partners. Conclusions: Gender-specific development of nonverbal behaviour may help to understand the development of gender differences in depression in adolescence. Females who fail to exhibit otheroriented social skills may be particularly at risk for depressive symptoms. Keywords: Depression, adolescence, nonverbal behaviour, gender differences, behavioural measures.
\end{abstract}

There is a steady increase in depressive symptoms from middle childhood into young adulthood, with a peak occurring during middle adolescence (Gutman \& Sameroff, 2004; Kessler, Avenevoli, \& Merikangas, 2001; Nolen-Hoeksema, Girgus, \& Seligman, 1992). Although a variety of etiological factors have been suggested for this increase during adolescence, including physiological (Graber, Lewinsohn, Seeley, \& Brooks-Gunn, 1997), cognitive (Nolen-Hoeksema \& Girgus, 1994), social (Petersen, Sargiani, \& Kennedy, 1991), and other factors (Hammen \& Rudolph, 1996), the present study focuses on the role of social skills deficits. There is ample evidence that depression is related to problems in social relationships, as indicated by children and adolescents themselves, their peers, teachers and parents (Connoly, Geller, Marton, \& Kutcher, 1992; Dalley, Bolocofsky, \& Karlin, 1994; Klein, Lewinsohn, \& Seeley, 1997; Puig-Antich et al., 1985a, 1985b). Furthermore, longitudinal studies indicate that a lack of popularity predicts (an increase in) depression, both in children (Boivin, Hymel, \& Bukowski, 1995; Cole, Martin, Powers, \& Truglio, 1996; Kupersmidt \& Patterson, 1991; Panak \& Garber, 1992; Wierzbicki \& McCabe, 1988) and adolescents (Nolan, Flynn, \& Garber, 2003).

The social skills deficits model (Coyne, 1976a, 1976b; Libet \& Lewinsohn, 1973; Segrin, 2000) describes how such problems may arise. Briefly, the model suggests that less optimal social skills may

Conflict of interest statement: No conflicts declared. lead to less positive responses or even rejection from important others, which, in turn, may lead to a negative self-image, loneliness and depression. Moreover, depression itself may have a negative impact on social skills, leading to even more negative responses from others. Though intriguing, there is a dearth of empirical research concerning the nature of social skills (and deficits) in adolescence and how this relates to individual differences in depression. Therefore, the present research includes two studies that examine differences in behaviour between mildly depressed and nondepressed (pre-)adolescents during conversations with an adult (study 1) and a same-aged peer (study 2). Both studies also examine whether conversation partners respond differently to a mildly depressed as compared to a nondepressed participant. By comparing both studies, we also examine whether differences in nonverbal social behaviours are a general finding or depend on the type of partner or situation. These differences are studied in non-referred, general population school samples, in order to describe the development of nonverbal behaviours and to track whether problematic social skills are detectable before depressive symptoms reach clinical levels.

As noted above, depressive symptoms increase in adolescence, both in the clinical range and in normative samples (Hankin et al., 1998; Nolen-Hoeksema, 1990). Moreover, gender differences in depression during childhood, if found, tend to favour males, but by mid-adolescence this difference is reversed, resulting in more depression among females 
which continues into middle adulthood (Petersen et al., 1991). Because of the general increase in depression during adolescence and the reversal of gender differences, the present studies were designed to specifically focus on social skills that are gender and/or age specific, or that show a gender- or age-specific link with depressive symptoms.

Nonverbal behaviours are interesting in this respect, because they differ between men and women. These differences (in part) develop as a result of display rules, which prescribe that women should behave in a friendlier, more attentive and other-oriented manner than men (DePaulo, 1992; Hall, 1984, 1987; LaFrance \& Hecht, 1999). As prescribed, adult women gaze more often while listening. Gazing while speaking is related to dominance and confidence, and gazing while listening indicates positive interest for the other person (Dovidio \& Ellyson, 1982; Exline, Ellyson, \& Long, 1975; Droney \& Brooks, 1992; Farabee, Holcom, Ramsey, \& Cole, 1993). The ratio between the two, labelled the visual dominance ratio, is larger in men than women (Dovidio, Brown, Holtman, Ellyson, \& Keating, 1988). Moreover, women show more backchannel behaviours (i.e., listener responses such as nodding that confirm the speaker without interrupting him), smile more often and are more likely than men to use a smile to mask negative emotions (Burgoon, 1994; DePaulo, 1992; Hall, 1984).

The display of nonverbal behaviour depends on age. During middle childhood children become increasingly capable of understanding display rules (Saarni \& Weber, 1999; Rotenberg \& Eisenberg, 1997), and they learn to adjust their behaviour accordingly (Cole, 1986; DePaulo, 1991; Gnepp \& Hess, 1986; Underwood, Coie, \& Herbsman, 1992), especially in the presence of peers (Zeman \& Garber, 1996). How these skills influence gender differences in the development of specific nonverbal behaviours such as gazing, smiling and backchannelling is less clear. Girls gaze more often than boys from infancy onwards, but gender differences further increase with age (Hall, 1984). In childhood, girls particularly show more gazing while speaking (Ashear \& Snortum, 1971; Podrouzek \& Furrow, 1988), indicating a higher visual dominance ratio than boys. When in development this ratio switches to favour males by adulthood is uncertain. Smiling in childhood does not seem to show a clear gender difference during communication with parents or peers (Hall, 1984), although girls do emit more smiles in response to negative experiences (Cole, 1986). Backchannel behaviours are rarely shown before the age of 8 years but increase thereafter, and girls show them more often than boys (Dittman, 1972; Hess \& Johnston, 1984). Surprisingly few studies investigate the gender-specific development of nonverbal behaviours between the ages of 12 and 18 years, therefore descriptive information from early adolescence to adulthood is lacking. The first purpose of the present research was to address this gap by investigating age and gender differences on a variety of nonverbal behaviours from late childhood through adolescence. We expected that as adolescents mature, they would increasingly behave according to genderspecific display rules.

The second purpose of this research was to examine the link between nonverbal behavioural displays and depression. As adolescent girls run more risk for developing depression than boys, one might expect the other-oriented girls' pattern of nonverbal communication to be a risk factor for depression. However, depressed adults do not show the typical female pattern. They gaze less and show fewer smiles and head-nods, both in clinical groups and in mildly depressed students (see review by Segrin, 2000). No studies are available on adolescents, but the few observation studies in depressed children seem to show similar lower rates of positive expressions as compared to their nondepressed peers, both in nonreferred (Altman \& Gotlib, 1988) and clinical samples (Kazdin, Esveldt-Dawson, Sherick, \& Colbus, 1985a). A possible explanation for the higher incidence of depression in adolescent girls may therefore be that not complying with gender-specific display rules has more negative consequences for girls than for boys. Girls' friendships are characterised by higher levels of intimacy as compared to boys (Hartup, 1996), thereby more often requiring the typical female pattern of nonverbal behaviour, i.e., being more pleasant and otheroriented (as indicated by smiling, backchannelling, gazing while listening, etc). Therefore, we expected that mildly depressed adolescents would show less positive behaviours compared to their peers, particularly girls. Moreover, given that less positive display behaviours would be regarded as more 'deviant' in girls than in boys, we expected that this, in turn, would result in girls receiving more negative responses from their communication partners than boys with similar deficits.

The third purpose of this research was to examine the role of interaction partner on nonverbal behavioural displays in relation to depressive symptoms. As peer relationships become increasingly important for social and identity development in adolescence, especially in girls (Hartup, 1996; Kroger, 2000), the link between depression and nonverbal behaviours may be evident only during peer interactions rather than during interactions with adults. Some findings seem to support this suggestion in children. Kazdin and colleagues (1985a) found differences in nonverbal behaviour during interactions with peers, but when observed during an interview with an adult the diagnosis of depression did not distinguish the nonverbal behaviour from that of children with other psychiatric diagnoses (Kazdin, Sherick, EsveldtDawson, \& Rancurello, 1985b). Differences in task characteristics and goals (e.g., more 'dominant' adult partner, clinical interview versus free play) across 
the two studies, with concomitant differences in the nonverbal behaviour of the partners across these conditions (Burgoon, Buller, \& Woodal, 1994), may be responsible for the peer/adult partner effect. Hence, research is needed that explicitly examines partner-age effects on nonverbal behaviours across the same tasks. Thus, the present research consists of two observational studies of dyadic interactions among adolescents, one in which the partner is an adult (study 1) and another in which partner is a same-aged peer (study 2).

In summary, the first aim of both studies is to describe age and gender differences in gazing (while speaking and while listening), backchannelling and smiling during adolescence. We hypothesise that girls will exhibit more 'other-oriented' behaviours than boys and that this gender difference will increase with age. The second aim is to investigate differences between mildly depressed adolescents and non-depressed controls in nonverbal behaviour and whether differences vary by age and gender. We hypothesise that depressed adolescents are less 'other-oriented', and these nonverbal deficits will be particularly problematic in older adolescent depressed females where display rules prescribe that other-oriented behaviours should be shown more frequently. Thirdly, the behaviours of the partner in conversation are examined in order to explore whether mildly depressed adolescents are responded to in a less positive way, and if such a response varies by age and/or gender. We hypothesise that the behaviour of depressed adolescents leads to discomfort and therefore less positive nonverbal behaviours in the partner as compared to partners of nondepressed adolescents. Again, this may be particularly true in (older) girls' conversations as low levels of other-oriented behaviours may be regarded as more negative in girls. Finally, the age of the partner is also investigated in order to clarify the role of the adults versus peers in eliciting behaviour from (depressed) adolescents. We hypothesise that differences between mildly depressed adolescents and controls would be more obvious during peer interactions than during conversations with an adult.

\section{Study I: Conversations with an adult}

\section{Methods}

Participants. Participants were 122 children (58 males, 64 females) selected on the basis of their depressive symptomatology from a larger sample $(N=606)$ of Dutch students from 8 different primary/secondary schools located in several cities/ small towns in the central part of the Netherlands (for more details see van Beek, 2006a). The 61 primary school children were in one of the last three years of school (Groups 6-8) with a mean age of 10.3 years $(S D=1.1)$ while the 61 secondary students were in their first or second year with a mean age of 13.9 years $(S D=.91)$. Participants were selected on the basis of a relatively high $(N=$ 56,27 boys) versus low ( $N=66,31$ boys) score on a Dutch version of the Children's Depression Inventory (Leuven \& van Beek, 2000). A cut-off score of $>10$ (i.e., $\geq$ P75) was taken as an indication of mild depression and control children had scores $\leq 7$ (i.e., $\leq$ median). ${ }^{1}$ Mean depression for the mildly depressed group was $15.7(S D=4.0)$ and for the nondepressed control group $3.5(S D=2.2)$. Age and gender groups had similar depression scores.

Instruments. Depression inventory. Depressive symptoms were measured by means of a Dutch version (Leuven \& van Beek, 2000) of the Children's Depression Inventory (Kovačs, 1992). In order to alleviate worries expressed by school directors and parents, one item from the original CDI concerning suicidal ideation was deleted and replaced by two less precarious questions concerning thoughts about death. Reliability was good (Cronbach alpha $=.81$ ). One month test-retest in part of the original sample $(n=248)$ resulted in a significant correlation, $r=.67, p<.001$, which is comparable with findings reported for the American version of the CDI, where correlations were found ranging from $r=.50$ (interval 6 weeks) to $r=.87$ (interval 1 week).

Observations. Conversations between participants and one of three female ${ }^{2}$ college students were videotaped for 8-12 minutes. The partners in conversation were seated in chairs placed at an angle of approximately 90 degrees. The child was facing the camera and the face of the adult partner was filmed from the side. The topic of conversation was relationships with peers. Children were encouraged to speak about both positive and negative experiences with peers. The experimenters also told short stories about such experiences (as if they happened to them once), creating prolonged listening periods in order to trigger listener responses from the children (similar stories across experimenters: more detailed information available from the first author). The child was unaware of the importance of nonverbal behaviours, as he/she had been told that filming was done to enable the analyses of the content of the conversation.

\footnotetext{
${ }^{1}$ The criterion of $>10$ was chosen instead of the more common cut-off of $\geq 13$ in order to create about equal group sizes for boys and girls with similar mean depression scores (in some age groups there were too few boys with scores $\geq 13$ ). Deletion of the 9 (study 1 ) or 11 (study 2) children with scores 11 or 12 did not change findings. Twenty per cent of the mildly depressed group in study 1 (both boys and girls) had scores between 20 and 25 (>19 = 'clinical' level according to Kovačs, 1992), but as durations and frequencies of their behaviours were not different from those with scores between 11 and 19, they were included in the mildly depressed group.

${ }^{2}$ Group sizes did not allow variation of the sex of the adult partner.
} 
The first 7 minutes of the recordings were coded for all participants. If there was some disturbance during the conversation (e.g., people accidentally entering the room), the period of disturbance was not used and coding continued until 7 minutes of undisturbed conversation elapsed. The following behaviours were observed in both partners in communication by means of real-time decoding of ongoing behaviour with the programme 'Observer 3.0':

- Gazing, i.e., onset and duration of eyes directed towards the inner part of the face of the partner. We calculated the frequency and percentage of looking time during the talk and listen periods separately, as well as the visual dominance ratio $(=$ ratio for \% looking while speaking to looking while listening). Only the results for percentage of gazing are presented, unless the frequencies or the visual dominance ratio provide important additional information.

- Talking, i.e., the onset and duration of speech (backchannel behaviours as defined below are not coded as speech).

- Backchannel behaviours, i.e., the frequency of nodding (or shaking) or vocal utterances such as 'yes', 'uhhuh', indicating interest and confirmation of what the partner was saying without interrupting the speech of the partner (Poyatos, 1983; Reid, 1995).

Also Smiling/laughing, i.e., the amount of positive facial expressions was coded. As both participants, particularly the adult, often showed a positive facial expression for extended periods, we could not reliably count the exact number of smiles. Therefore, we used a 5-point Likert scale running from "hardly any positive expressions' to 'positive expressions for most of the time'.

All variables were normally distributed, except the frequency of backchannel behaviours due to a large absence of these behaviours in the younger children. A square-root transformation of backchannel scores was used to solve this problem.

The students that made and analysed the recordings were unaware of the depression score of the participants during the conversation and during the analyses of the video-recordings. Each of the three adult partners spoke with about equal numbers of boys and girls, primary or secondary school and depressed or nondepressed participants. Inter-observer reliability was tested by double-coding twelve recordings. Allowing for a difference in timing of 1 second, mean agreement was above $90 \%$ for all behaviours $^{3}$ and Pearson correlations of the frequency of these behaviours were all >.95.

\footnotetext{
${ }^{3}$ New coders were trained by experienced students and they double-coded tapes from the original inter-observer reliability study as well as recently coded tapes. As reliability was high for all recordings, no indications were found for observer drift.
}

\section{Results}

Child behaviour. A $2 \times 2 \times 2$ MANOVA was conducted with looking, talking and backchannel behaviours as dependent and age (primary-secondary school), gender (boy-girl) and depression (mildly depressed-control) as independent variables. For the combined dependent variables (using Wilks' Lambda) a main effect for gender, $F(4,111)=10.42$, $p<.001$, a main effect for age, $F(4,111)=14.96$, $p<.001$, and an age $\times$ gender interaction, $F(4$, $111)=3.45, \quad p=.011$, were found. Depression showed a nonsignificant trend for a main effect, $F(4$, $111)=2.19, p=.075$. None of the interaction effects with depression were significant.

As shown in Figure 1, analyses of the separate dependent variables indicated that girls showed more looking while talking, $F(1,121)=16.01$, $p<.001$, more looking while listening, $F(1,121)=$ $29.1, p<.001$ and more backchannel behaviours, $F$ $(1,121)=16.38, p<.001$ than boys. There was no gender difference in talking (children talked about

\section{a. percentage of time looking during talking}

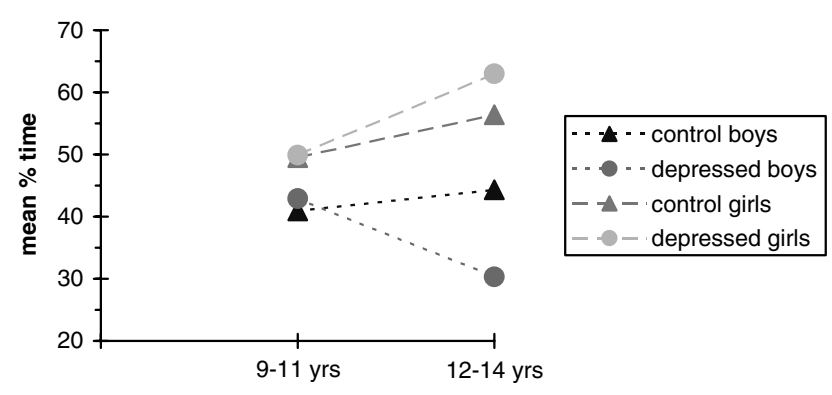

b. percentage of time looking during listening

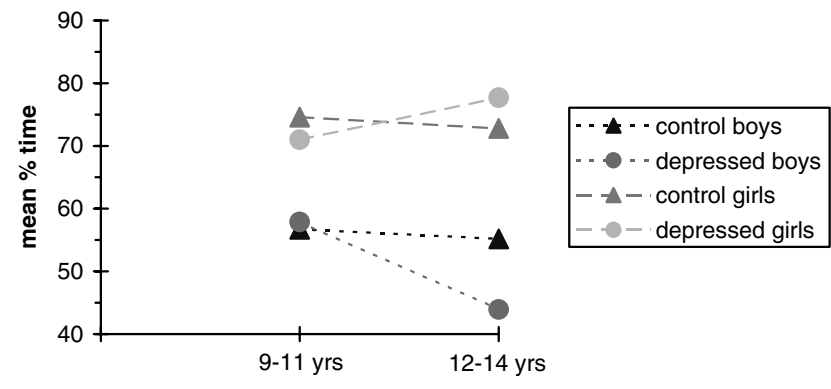

c. frequency of backchanneling

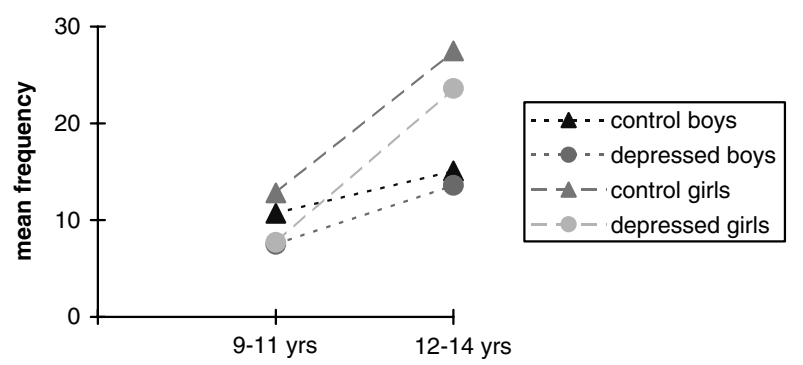

Figure 1 Effects of age, gender and mild depression on child/adolescent behaviours during conversation with an adult 
$46 \%$ of the time) or in visual dominance. A significant increase with age, $F(1,121)=55.52, p<.001$ and a significant age $\times$ gender interaction, $F(1,121)=$ 10.26, $p=.002$, were found for backchannelling. While no gender differences were observed among the primary school students, secondary school females backchannelled more often than their male counterparts. Mildly depressed students showed fewer backchannel behaviours than nondepressed students, $F(1,121)=7.29, p=.008$, and no main or interaction effects of depression on looking or talking were found. As smiling was measured on a different scale and did not correlate with the other variables, analyses were done by a separate ANOVA. No age, gender or depression effects on smiling were found.

Adult behaviour. A similar MANOVA was done for the adult's behaviours. The multivariate analyses revealed no significant effects for the combined dependent variables, only a nonsignificant tendency for an age $\times$ depression interaction effect, $F(4$, $111)=2.13, p=.082$. Analyses of the separate independent variables revealed that this effect was not present in gazing, but only in backchannel behaviours, $F(1,121)=4.22, p=.042$. Figure 2 shows that the adults demonstrated fewer backchannels with depressed elementary students than their nondepressed peers but showed more backchannels with depressed secondary students than their nondepressed counterparts.

No effects of age, gender or depression were found on adult talking. Adults talked around $43 \%$ of the time. No significant differences were found for gazing or smiling either. The adults looked at the child for $73 \%$ of the time during talking and $97 \%$ of the time during listening and showed a positive expression most of the time.

\section{Conclusion and discussion}

Looking behaviours showed the well-known pattern in relation to talking and listening (Burgoon et al.,

\section{frequency of adult backchanneling}

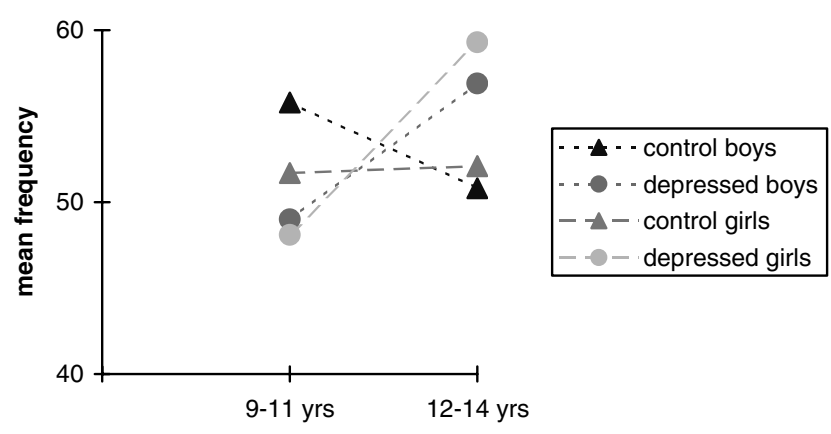

Figure 2 Effects of age, gender and mild depression of the children and adolescents on backchannel behaviours of the adult
1994), as both adults and children looked at the partner more during listening than during talking. The adult behaviour was not much affected by age or gender of the child, despite clear difference in children's behaviour. Girls looked at the adult more than boys at both ages, both while speaking and while listening, whereas previous studies in younger children only reported more gazing in girls while speaking (Ashear \& Snortum, 1971). No gender difference was seen in the visual dominance ratio. Backchannel behaviours showed a gender-specific development, in that females showed them more often than males in the secondary school group, while no gender difference was found in the elementary school group. This is in concordance with previous studies on the development of backchannel behaviour (Dittman, 1972; Hess \& Johnston, 1984). No gender or age differences were found for smiling, consistent with what has been found for children (Hall, 1984).

Few differences between the mildly depressed and nondepressed groups were observed. With respect to the behaviour of the children and adolescents, the mildly depressed only showed less backchannel behaviours than their nondepressed counterparts. Gender and age did not moderate this difference. With respect to the behaviour of the adult partner, again differences were found only on backchannel behaviours. The adult partner backchannelled depressed children less often than nondepressed children in the young group, but clearly showed the opposite pattern in the secondary school group. The adult may have been attempting to encourage the adolescent to show more of this behaviour or to be more supportive. The latter tendency was also found in psychiatrists' behaviour during interviews with severely versus less depressed adults (Geerts, Bouhuys, \& Bloem, 1997). That the adult partner in the present study did not react this way in the younger group could mean that the difference in child behaviour may not have been so apparent there (frequency of backchannelling was low even in the nondepressed group) or was attributed a different meaning/importance because of their younger age.

\section{Study 2: Conversations with same-sex peers Methods}

Participants. Participants were 154 adolescents $(73$ boys and 81 girls) selected on the basis of their depressive symptomatology from a second, larger, ongoing study of adolescents conducted in two secondary schools each from a different city in the western part of the Netherlands. The younger adolescents $(N=81)$ were drawn from first year students (mean age $=13.1, S D=.5$ ) and older adolescents were in their fourth year of study (mean age $=16.2, S D=.6)$. Participants were selected on the basis of a relatively high $(N=59,25$ males $)$ 
versus low $(N=95,48$ males) score on the Children's Depression Inventory (see study 1). Mean depression score for the mildly depressed group was $14.8(S D=3.7)^{4}$ and for the nondepressed control group $2.5(S D=2.0)$. Age and gender groups had similar depression scores.

Procedures. Pairs of participants were observed at school in an empty (class)room in a situation similar to the one described in study 1 , except that the partner was a same-age, same-sex peer. The partner was not usually a classmate, but if so, he/she was not a good friend. This was done to avoid influences on behaviour caused by large differences in the quality of relationships. The topic of conversation was a social dilemma concerning relationships with peers (more details available from the authors). Dyads were instructed to discuss the issue until they agreed on the best solution. If participants agreed on a solution and had discussed all possible consequences before 5 minutes elapsed, they were asked to try to agree upon a top- 5 ranking on various issues (such as the most popular teachers, or the most important characteristics of friendships) until 5 minutes of conversation occurred. Five minutes of conversation were coded for each dyad. Participants were unaware of the importance of their nonverbal behaviours.

Dyads consisted of a depressed and a nondepressed adolescent or of two nondepressed adolescents. The behaviour of depressed adolescents was not compared with that of their own conversational partners, because behaviours tend to converge to each other during interaction (Burgoon, 1994), which may negatively influence the behaviour of the nondepressed partner. Instead, comparisons were made with nondepressed children who had been talking to another nondepressed peer (in 51 cases the same ones the depressed adolescents had been talking to). Moreover, in order to examine whether depressed adolescents were responded to in a less positive way, 51 of the nondepressed adolescents were filmed twice, once with a depressed and once with a nondepressed peer (in random order).

Gazing, talking and backchannelling were coded as described for study 1 , but the frequencies of smiling/laughing during listening were now coded by means of the Observer programme. Inter-observer reliabilities were tested by double-coding $20 \%$ of the recording. After training, the mean agreement ranged from 87 to $89 \%$ and Spearman correlations (r) ranged from .91 to .99. Mean intra-observer agreement (6 recordings) was above $90 \%$ for all behaviours.

Coding of the tapes was done by three different groups of students, who did not necessarily code

\footnotetext{
${ }^{4}$ In this study $11 \%$ of the mildly depressed children had scores between 20 and 27. Deletion of these participants did not change findings.
}

the same (or the same segment of) conversations (due to some problems with quality of the recordings and to the fact that some recordings were not yet available for the first group of students). Therefore, not all behaviours were coded for all 154 participants. Because all behaviours were coded for only 72 participants, yet some behaviours were coded for all participants, we conducted our analyses separately per behaviour in order to maximise our sample size. Thus, only looking behaviours were analysed by means of multivariate analyses, while the other behaviours were analysed using ANOVA. As in study 1, a square-root transformation was necessary for the frequency of backchannel behaviours.

\section{Results}

Effects of age, gender and mild depression on nonverbal behaviours. A $2 \times 2 \times 2$ MANOVA was conducted with the percentage of looking while speaking and the percentage of looking while listening as dependent, and age (13 or 16 years old), gender (boy-girl) and depression (mildly depressedcontrol) as independent variables. For the combined dependent variables a multivariate main effect for gender, $F(2,137)=10.59, p<.001$, an age $\times$ gender interaction, $F(2,137)=3.66, \quad p=.028$ and a depression $\times$ gender interaction, $F(2,137)=3.44$, $p=.035$ were found.

Although a main effect of gender was found on looking while listening, $F(1,145)=17.1, p<.001$, this was qualified by a gender $\times$ age interaction, $F(1$, 145 ) $=5.3, p=.023$ (see Figure 3b). The gender difference in gazing while listening was more apparent for the older adolescents rather than younger adolescents, with older adolescent females demonstrating more looking while listening than older adolescent males. The gender $\times$ age interaction for looking while speaking was also significant, $F(1$, $145)=7.0, p=.009$, showing a similar pattern as looking while listening. The visual dominance ratio was significantly higher in boys (.72) than girls (.56), $F(1,145)=4.6, p=.034$, and no age or gender $\times$ age interaction effects were found. Furthermore, a gender $\times$ depression interaction revealed that mildly depressed girls compared to nondepressed females looked less while listening, while no differences between mildly depressed and nondepressed males on this behaviour were found, $F(1,145)=4.6$, $p=.028$.

For smiling a $2 \times 2 \times 2$ ANOVA revealed a main effect of gender, $F(1,79)=4.65, p=.034$, with males smiling less often than girls, that was qualified by an age $\times$ gender interaction, $F(1,79)=7.3, p=.009$. The frequency of smiling was higher in older as compared to younger females, whereas the reversed pattern was found for older versus younger males. Although findings in Figure $3 \mathrm{c}$ seem to indicate that mildly depressed adolescents show fewer smiles than 
a. percentage of time looking during talking

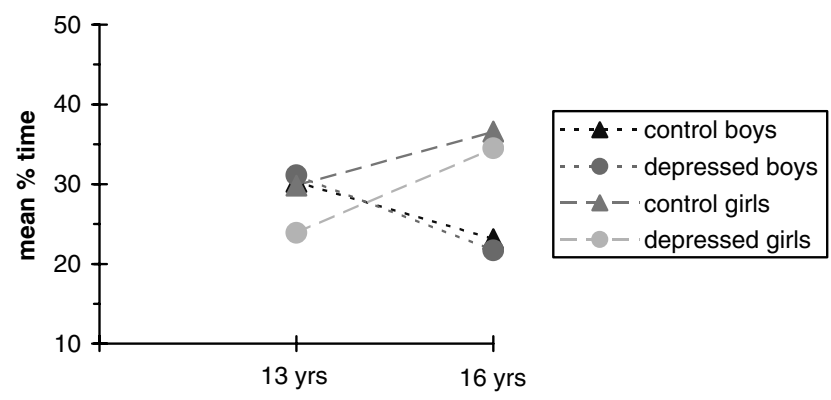

b. percentage of time looking during listening

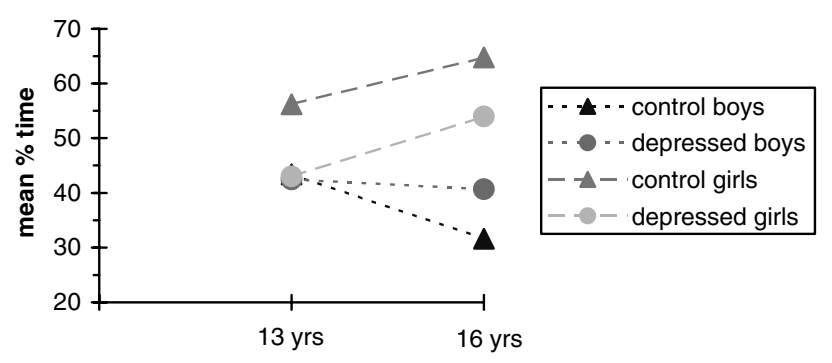

c. frequency of smiling

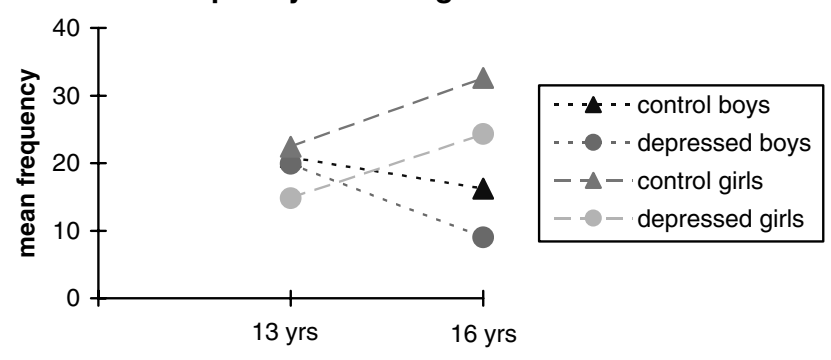

Figure 3 Effects of age, gender and mild depression on adolescents' gazing and smiling during conversations with peers

nondepressed adolescents, this difference just missed significance, $F(1,79)=3.38, p=.07$.

The ANOVA for the percentage of talking revealed a significant effect for age, in that the older adolescents talked slightly more than the younger adolescents $(M=35.1$ and $M=30.7$, respectively), $F(1$, $145)=4.6, p=.034$. No effects of gender and/or depression on talking behaviour were found. Results were similar for backchannel behaviours, with the only significant finding being a main effect of age, $F(1,145)=5.45, p=.012$. Again, older adolescents showed more backchannelling than younger adolescents ( $M=6.5$ and $M=4.3$ respectively).

Behaviour towards a mildly depressed partner. Fifty-one adolescents talked to both a mildly depressed and a nondepressed partner. Repeated measures ANOVAs were conducted with behaviour towards the depressed versus the nondepressed partner as the within factor, and age and gender as between factors. Because age and gender differences have already been described above for a larger group, we report only the findings for the within a. percentage of time looking during talking

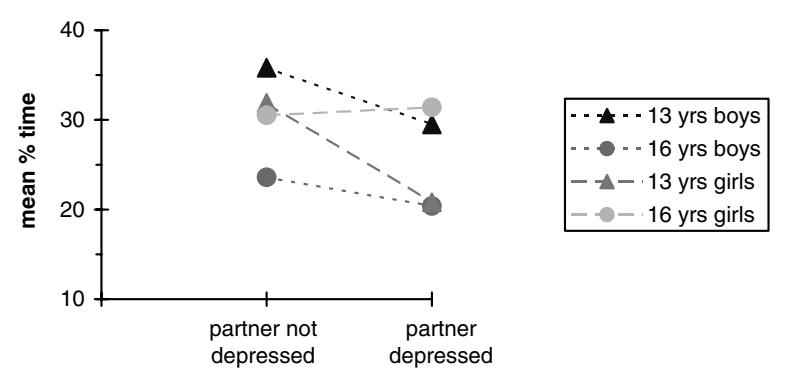

b. percentage of time looking during listening
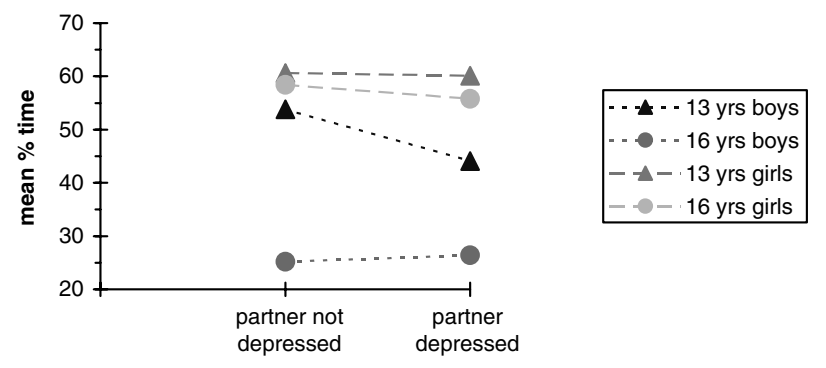

c. frequency of smiling
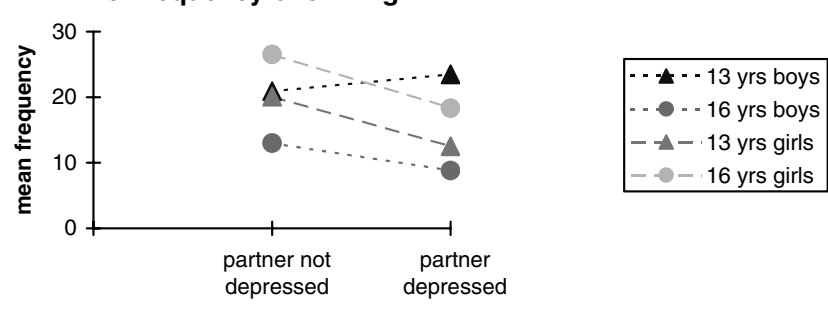

Figure 4 Effects on gazing and smiling of having a mildly depressed partner in the different age and gender groups

factor and its interaction with age and gender (see Figure 4).

When expressed in terms of the visual dominance ratio, a significant depressed partner $\times$ age $\times$ gender interaction was found, $F(1,47)=5.15, p=$ .028 , with younger adolescent females showing a lower ratio when talking to a depressed partner compared to all other groups. As shown in Figure $4 \mathrm{a}$ and $4 \mathrm{~b}$, this was particularly caused by less gazing while talking, although for each separate looking behaviour differences were not significant (however, there was a trend for the effect of mild depression on looking while talking, $F(1,47)=$ 3.52, $p=.067$ ).

As shown in Figure 4c, adolescents smiled less often towards a mildly depressed than a nondepressed partner, $F(1,38)=5.1, p=.03$. No significant effects of having a mildly depressed partner were found for either the percentage of talking or the frequency of backchannel behaviour.

\section{Conclusion and discussion}

Adolescent females gazed more (particularly while listening), showed a lower visual dominance ratio, 
and smiled more often than adolescent males, replicating the gender-specific pattern found for these behaviours among adults (Dovidio et al., 1988; Hall, 1984). The similarity with adults was greater in the older adolescents as gender differences increased with age. Gazing and smiling were higher in the older female adolescents compared to the younger ones, whereas the reversed pattern was found for males. The frequency of backchannels was quite low, but increased with age. In contrast to study 1 and other studies (Dittman, 1972; Hess \& Johnston, 1984), no gender difference was found. Perhaps the low frequency of backchannels in the communication task of this study was responsible for this finding.

The behaviour of mildly depressed adolescent females compared to nondepressed adolescent females showed significantly less looking while listening, while no differences between depressed and nondepressed adolescent males were observed. Although previous studies reported less gazing in depressed adults and children (Segrin, 2000; Kazdin et al., 1985a), the current study identified this effect for gazing while listening and that during adolescence this difference is seen in girls. As looking while listening indicates (positive) interest, normally expected from and indeed shown more often by females than males, it appears that depressed girls may not be acting according to gender-specific display rules.

In the partner's behaviour the visual dominance ratio was lower towards a mildly depressed as compared to a nondepressed partner, but only among the younger adolescent females. As looking while speaking is linked with confidence (when high) or anxiety (when low), this may indicate that they felt less comfortable when communicating with a mildly depressed partner (Farabee et al., 1993). Why this effect was mostly seen in the 13-year-old girls remains an open question. Perhaps older adolescents were more confident or more polite. A stronger and more general effect on the partner's behaviour was found for smiling. Mildly depressed adolescents received fewer smiles.

\section{General discussion}

\section{Gender and age effects on nonverbal behaviours in adolescence}

This paper is the first to provide information about how gender-specific nonverbal behaviours change during adolescence into a pattern more similar to that in adults (Hall, 1984). As expected, genderspecific display rules were more visible in the behaviour of older adolescents, although different age effects were found for each of the behaviours observed.

Females gazed at their partners more than males in both studies, replicating the results described for both children and adults (Hall, 1984). During peer interactions a gender difference was most clearly found for gazing while listening, suggesting an increased importance of this behaviour with age in girls. Confirming previous findings in adults (Dovidio et al., 1988), both 13- and 16-year-old boys showed a higher visual dominance ratio than girls, but only during peer interactions. As we did not study peer dyads in the 9-11-year-olds, we do not know whether the same gender difference exists at this age or when this gender difference first emerges. The lack of age differences in study 1 is in concordance with previous findings from studies describing the relative stability in gazing between 10 and 12 years, when talking to both adults and peers (Ashear \& Snortum, 1971; Levine \& SuttonSmith, 1973). These earlier studies also found an increase after the age of 12 , but in the present study this was only found in girls, whereas in boys gazing decreased with age. The increase in girls is in line with gender-specific display rules that prescribe that women should behave in a more 'otheroriented' manner (DePaulo, 1992; Hall, 1984). In males, high levels of gazing may be interpreted as either 'threatening/dominant' (while speaking) or too 'intimate' (while listening) (Dovidio \& Ellyson, 1982; Exline et al., 1975), and perhaps boys adapt their behaviour according to this line of interpretation.

Backchannel behaviours increased with age in both studies, again confirming previous findings (Dittman, 1972; Hess \& Johnston, 1984). In study 1, 13-year-old females backchannelled more than 13year-old males but no gender differences among the 10-year-olds were found, suggesting that gender differences increase with age during interaction with adults. In the peer dyads backchannel behaviours were generally less frequent and no gender differences were found. The higher frequency of backchannels emitted by the adult as well as the short stories they told (creating prolonged listening periods) might be responsible for the fact that gender differences were found only in study 1 .

Confirming the gender difference found among adults, older adolescent females showed a higher frequency of smiling than their male counterparts (Hall, 1984). No gender differences were found among the younger adolescents, suggesting that this difference emerges during middle adolescence somewhere between the ages of 13 and 16 . Whether this gender divergence occurs at the same age for adolescent-adult interactions cannot be addressed with the current data but needs to be examined in future research.

In summary, as expected, adolescents increasingly behaved according to gender-specific display rules (Burgoon, 1994; Hall, 1984; DePaulo, 1992), although the age at which gender differences were shown also depended on the type of partner and task characteristics. 


\section{Differences between mildly depressed and nondepressed adolescents}

The effect of mild depression was clearly different between the two studies. Study 1 showed differences only in backchannel behaviours, whereas in study 2 both gazing and smiling were shown less frequently in the mildly depressed group. Although this may be partly due to age differences of the participants across studies, comparison of the oldest group of study 1 (13-year-olds) with the youngest group of study 2 (also 13-year-olds) suggests a partner effect (although we did not compare both types of partners in the same children). One explanation might be that the more 'dominant' adult stimulated gazing and smiling, even in depressed children, as these behaviours are known to be shown more often by submissives (Burgoon et al., 1994), while peer interactions might elicit more anxiety in mildly depressed children and adolescents because of earlier negative experiences with peers and/or higher fear of rejection, resulting in a dampening of gazing and smiling behaviours. Nevertheless, differences were found on backchannel behaviours between mildly depressed and nondepressed children and adolescents when interacting with an adult, perhaps because these behaviours are emitted less consciously and therefore are less regulated than gazing (DePaulo, 1992). For clinical practice and research it is important to realise that during conversations with adult clinicians depressed youth may not show less than optimal performance on certain nonverbal behaviours. Observations of peer dyads may provide more information, or interviews should be organised in such a way that more subtle differences in less regulated behaviours indicating lower 'otherorientedness' (e.g., backchannels or postures) can be detected.

The differences in behaviour were not the same for the mildly depressed adolescent and his/her partner. Thus, the partner did not simply mirror the other participant's behaviour. In the older group of study 1 the adult responded to the lower frequency of backchannel behaviours in the mildly depressed adolescent with more backchannel behaviours. In study 2, mildly depressed adolescent females gazed less during listening, whereas partners of depressed adolescents smiled less often. As such, partial support has been found for our hypothesis that the behaviour of mildly depressed adolescents, and particularly that of girls talking to peers, showed signs of a lower capacity or motivation to behave according to gender-specific rules. Moreover, peer partners showed less positive responses when talking to mildly depressed peers, providing additional support for the social skill deficits theory (Coyne, 1976a; Segrin \& Abramson, 1994).

Finally, some effects of mild depression were only present in girls, suggesting that the social skills deficit model may be particularly relevant for explaining the gender-linked divergence in risk for depression during adolescence. This may be because the level of other-oriented behaviours is usually higher in girls than boys, so that a lack of motivation in this regard or the presence of social anxiety is more noticeable. For females, other-oriented behaviours are regarded as more important for the quality of communication (Hartup, 1996), in that deficits or levels that are lower than expected may cause a larger negative response by a partner interacting with a female rather than a male. However, not all findings were gender-specific, with some responses also observed in partners of depressed boys. This suggests that other behaviours than the ones coded in the present study also played a role. Possible candidates are negative behaviours, such as disruptiveness or aggression (Altman \& Gotlib, 1988), or speech characteristics such as intonation, speech volume and postural and gestural behaviours that are known to be different in depressed adults (Segrin, 2000).

In conclusion, the findings show that nonverbal behaviours differ between mildly depressed and nondepressed adolescents, even in a nonreferred group, and that these differences resemble those of clinically depressed adults (Segrin, 2000). This suggests that such deficits are not just the result of clinical depression, but also accompany milder forms of depression. The findings also point to the importance of gender-specific social development in adolescence. Gazing, smiling and backchannelling are expected more from, and are indeed shown more often by, girls than boys, particularly when older, and reduced rates of these behaviours are related to mild depression, particularly in girls. However, the present study cannot determine the causal links between mild depression and nonverbal behaviour. Longitudinal research is necessary to find out if deviances in the gender-specific development of nonverbal behaviours can predict an increase in depression, and eventually more profound depressive problems, as suggested by the social skills deficits model. Lower involvement behaviours while interacting with a partner or the lack of coordination of nonverbal cues to the behaviour of an interaction partner has been found to predict the recurrence of depression in adults (Bos, Geerts, \& Bouhuys, 2002; Bos, Bouhuys, Geerts, van Os, \& Ormel, in press). If nonverbal behaviours can predict depression, the link between the development of these behaviours and other social skills, such as emotion decoding (van Beek, 2006b; Herba \& Philips, 2004; Pine et al., 2004) and more general measures of problems in social relationships (as in Nolan et al., 2003), needs to be investigated in order to better understand the possible mechanisms leading to depression. Of course, how problematic social skills relate to other well-known risk factors for the development of depression in adolescence, such as early maturation (Graber et al., 1997) or life-events (Sund, Larsson, \& 
Wichstrøm, 2003), should also be investigated in order to clarify how social, biological and cognitive factors coalesce in the etiology of depression. Social skills could act as an independent risk factor, could increase vulnerability for, or could act as a moderator or mediator of, these other factors (e.g., Bos, 2005; Hammen \& Rudolph, 1996). The present study indicates that it seems worth while to include nonverbal behaviours in explanatory theories for the gender-specific development of depression in adolescence.

\section{Acknowledgements}

The authors wish to thank B. van den Acker, I. van Oosten, H. van Dasler, M. Weerheim, M. Hopman, E. van der Reijden, M. Raaijmakers, E. Boer, A. van Duijn, J. Winkelhof and F. Fetter for their help in gathering and coding the video recordings.

\section{Correspondence to}

Yolanda van Beek, Developmental Psychology, Utrecht University, Heidelberglaan 1, 3584 CS Utrecht. The Netherlands; Tel: +31-30-2534059; Fax: +31-30-2534777; Email: y.vanbeek@fss.uu.nl

\section{References}

Altman, E.O., \& Gotlib, I.H. (1988). The social behavior of depressed children: An observational study. Journal of Abnormal Child Psychology, 16, 29-44.

Ashear, V., \& Snortum, J.R. (1971). Eye contact in children as a function of age, sex, social and intellective variables. Developmental Psychology, 4, 479.

van Beek, Y. (2006a, submitted). Age and gender differences in the attribution of meaning to facial expressions and postures in adolescence. Journal of Nonverbal Behavior.

van Beek, Y. (2006b, submitted). The attribution of negative emotional and interpersonal meaning to facial expressions and postures and depressive symptoms in adolescence. Journal of Nonverbal Behavior.

Boivin, M., Hymel, S., \& Bukowski, W.M. (1995). The roles of social withdrawal, peer rejection, and victimization by peers in predicting loneliness and depressed mood in childhood. Development and Psychopathology, 7, 765-785.

Bos, E.H. (2005). Interpersonal mechanisms in recurrence of depression. $\mathrm{PhD}$ thesis: Rijksuniversiteit Groningen.

Bos, E.H., Geerts, E., \& Bouhuys, A.L. (2002). Nonverbal interaction involvement as an indicator of prognosis in remitted depressed subjects. Psychiatry Research, 113, 269-277.

Bos, E.H., Bouhuys, A.L., Geerts, E., van Os, T.W.D.P., \& Ormel, J. (in press). Lack of association between conversation partners' nonverbal behavior predicts recurrence of depression, independently of personality. Psychiatry Research.
Burgoon, J.K. (1994). Nonverbal signals. In M.L. Knapp $\&$ G.R. Miller (Eds.), Handbook of interpersonal communication (2nd edn, pp. 344-390). Beverly Hills, CA: Sage Publications.

Burgoon, J.K., Buller, D.B., \& Woodal, W.G. (1994). Nonverbal communication: The unspoken dialogue. Columbus, Ohio: Greyden Press.

Cole, D.A., Martin, J.M., Powers, B., \& Truglio, R. (1996). Modelling causal relationships between academic and social competence and depression: A multitrait-multimethod longitudinal study of children. Journal of Abnormal Psychology, 105, 258270.

Cole, P.M. (1986). Children's spontaneous control of facial expression. Child Development, 57, 13091321.

Connoly, J., Geller, S., Marton, P., \& Kutcher, S. (1992). Peer responses to social interaction with depressed children. Journal of Clinical Child Psychology, 55, 365-370.

Coyne, J.C. (1976a). Depression and the response of others. Journal of Abnormal Psychology, 83, 186-193.

Coyne, J.C. (1976b). Toward an interactional description of depression. Psychiatry, 39, 28-40.

Dalley, M.B., Bolocofsky, D.N., \& Karlin, N.J. (1994). Teacher-ratings and self-ratings of social competency in adolescents with low- and high-depressive symptoms. Journal of Abnormal Child Psychology, 22, 477485.

DePaulo, B.M. (1991). Nonverbal behavior and selfpresentation: A developmental perspective. In R.S. Feldman \& B. Rime (Eds.), Fundamentals of nonverbal behavior (pp, 351-397). Cambridge: Cambridge University Press.

DePaulo, B.M. (1992). Nonverbal behavior and selfpresentation. Psychological Bulletin, 111, 203-243.

Dittman, A.T. (1972). Developmental factors in conversational behavior. The Journal of Communication, 22, 404-423.

Dovidio, J.F., Brown, C.E., Heltman, K., Ellyson, S.L., \& Keating, C.E. (1988). The relationship of visual power to visual displays of dominance between men and women. Journal of Personality and Social Psychology, 54, 233-242.

Dovidio, J.F., \& Ellyson, S.L. (1982). Decoding visual dominance behavior: Attributions of power based on relative percentages of looking while speaking and looking while listening. Social Psychology Quarterly, 45, 106-113.

Droney, J.M., \& Brooks, C.I. (1992). Attributions of selfesteem as a function of duration of eye contact. The Journal of Social Psychology, 133, 715-722.

Exline, R.V., Ellyson, S.K., \& Long, B. (1975). Visual behavior as an aspect of power role relationships. In P. Pliner, L. Krames, \& T. Alloway (Eds.), Nonverbal communication of aggression (pp. 21-52). New York: Plenum.

Farabee, D.J., Holcom, M.L., Ramsey, S.L., \& Cole, S.G. (1993). Social anxiety and speaker gaze in a persuasive atmosphere. Journal of Research in Personality, 27, 365-376.

Geerts, E., Bouhuys, A.L., \& Bloem, G.M. (1997). Nonverbal support giving induces nonverbal support seeking in depressed patients. Journal of Clinical Psychology, 53, 35-39. 
Gnepp, J., \& Hess, D.L.R. (1986). Children's understanding of verbal and facial display rules. Developmental Psychology, 22, 103-108.

Graber, J.A., Lewinsohn, P.M., Seeley, J.R., \& BrooksGunn, J. (1997). Is psychopathology associated with the timing of pubertal development? Child and Adolescent Psychiatry, 36, 1768-1776.

Gutman, L.M., \& Sameroff, A.J. (2004). Continuities in depression from adolescence to young adulthood: Contrasting ecological influences. Development and Psychopathology, 16, 967-984.

Hall, J. (1984). Non-verbal sex differences: Communication accuracy and expressive style. Baltimore, MD: The John Hopkins University Press.

Hall, J.A. (1987). On explaining gender differences. The case of nonverbal communication. Review of Personality and Social Psychology, 7, 177-200.

Hammen, C., \& Rudolph, K.C. (1996). Childhood depression. In E.J. Mash \& R.A. Barkley (Eds.), Child psychopathology (pp. 153-195). New York: Guilford.

Hankin, B.L., Abramson, L.Y., Agell, K.E., McGee, R., Moffit, T.E., \& Silva, P.A. (1998). Development of depression from preadolescence to young adulthood: Emerging differences in a 10-year longitudinal study. Journal of Abnormal Psychology, 107, 128-140.

Hartup, W.W. (1996). The company they keep: Friendships and their developmental significance. Child Development, 67, 1-13.

Herba, C., \& Philips, M. (2004). Annotation: Development of facial expression recognition from childhood to adolescence: Behavioral and neurological perspectives. Journal of Child Psychology and Psychiatry, 45, 1185-1198.

Hess, L.J., \& Johnston, J.R. (1984). Acquisition of backchannel listener responses to adequate messages. Discourse Processes, 11, 319-335.

Kazdin, A.E., Esveldt-Dawson, K., Sherick, R.B., \& Colbus, D. (1985a). Assessment of overt behavior and childhood depression among psychiatrically disturbed children. Journal of Consulting and Clinical Psychology, 53, 201-210.

Kazdin, A.E., Sherick, R.B., Esveldt-Dawson, K., \& Rancurello, M.D. (1985b). Nonverbal behavior and childhood depression. Journal of the American Academy of Child Psychiatry, 24, 303-309.

Kessler, R.C., Avenevoli, S., \& Merikangas, K.R. (2001). Mood disorders in children and adolescents: An epidemiologic perspective. Biological Psychiatry, 49, 1002-1014.

Klein, D.N., Lewinsohn, P.M., \& Seeley, J.R. (1997). Psychosocial characteristics of adolescents with a past history of dysthemic disorder: Comparisons with adolescents with past histories of major depression and non-affective disorders and never mentally ill controls. Journal of Affective Disorders, 42, 127-135.

Kovačs, M. (1992). Children's Depression Inventory, Manual. New York/Toronto: Multi-Health Systems, inc.

Kroger, J. (2000). Identity development, adolescence through adulthood. Thousand Oaks, CA: Sage Publications.

Kupersmidt, J.B., \& Patterson, C.J. (1991). Childhood peer rejection, aggression, withdrawal, and perceived competence as predictors of self-reported behavior problems in pre-adolescence. Journal of Abnormal Child Psychology, 48, 427-449.

LaFrance, M., \& Hecht, M.A. (1999). Option or obligation to smile: The effects of power and gender on facial expression. In P. Philippot, R.S. Fledman, \& E.J. Coats (Eds.), The social context of nonverbal behavior (pp. 45-70). Paris: Cambridge University Press.

Leuven, M., \& van Beek, Y. (2000). Children's Depression Inventory, Nederlandse Bewerking. Internal Report, Utrecht, The Netherlands: Utrecht University.

Levine, M.H., \& Sutton-Smith, B. (1973). Effects of age, sex and task on visual behavior during dyadic interaction. Developmental Psychology, 9, 400-405.

Libet, J.M., \& Lewinsohn, P.M. (1973). Concept of social skill with special reference to the behavior of depressed persons. Journal of Consulting and Clinical Psychology, 40, 304-312.

Nolan, S.A., Flynn, C., \& Garber, J. (2003). Prospective relations between rejection and depression in young adolescents. Journal of Personality and Social Psychology, 85, 745-755.

Nolen-Hoeksema, S. (1990). Sex difference in depression. Stanford: Stanford University Press.

Nolen-Hoeksema, S., \& Girgus, J.S. (1994). The emergence of gender differences in depression during adolescence. Psychological Bulletin, 115, 424-443.

Nolen-Hoeksema, S., Girgus, J.S., \& Seligman, M.E.P. (1992). Predictors and consequences of childhood depressive symptoms: A 5-year longitudinal study. Journal of Abnormal Psychology, 3, 405-422.

Panak, W.F., \& Garber, J. (1992). Role of aggression, rejection and attributions in the prediction of depression in children. Development and Psychopathology, 4, 145-165.

Petersen, A.C., Sarigiani, P.A., \& Kennedy, R.E. (1991). Adolescent depression. Why more girls? Journal of Youth and Adolescence, 20, 247-271.

Pine, D.S., Lissek, S., Klein, R.G., Mannuzza, S., Moulton, J.L., Guardino, M., \& Woldehawariat, G. (2004). Face-memory and emotion: Associations with major depression in children and adolescents. Journal of Child Psychology and Psychiatry, 45, 11991208.

Podrouzek, W., \& Furrow, D. (1988). Preschoolers' use of eye contact while speaking: The influence of sex, age and conversational partner. Journal of Psycholinguistic Research, 17, 89-98.

Poyatos, F. (1983). New perspectives in nonverbal communication: Studies in cultural anthropology, social psychology, linguistics, literature and semiotics. Oxford: Pergamon Press.

Puig-Antich, J., Lukens, E., Davies, M., Goetz, D., Brennan-Quattrock, J., \& Todak, G. (1985a). Psychosocial functioning in prepubertal major depressive disorders: I. Interpersonal relationships during the depressive episode. Archives of General Psychiatry, 42, 500-508.

Puig-Antich, J., Lukens, E., Davies, M., Goetz, D., Brennan-Quattrock, J., \& Todak, G. (1985b). Psychosocial functioning in prepubertal major depressive disorders: II. Interpersonal relationships after sustained recovery from the affective episode. Archives of General Psychiatry, 42, 511-517.

Reid, J. (1995). A study of gender differences in minimal responses. Journal of Pragmatics, 24, 489-512. 
Rotenberg, K.J., \& Eisenberg, N. (1997). Developmental differences in the understanding of and reaction to other's inhibition of emotional expression. Developmental Psychology, 33, 526-537.

Saarni, C., \& Weber, H. (1999). Emotional displays and dissemblance in childhood: Implications for selfpresentation. In P. Philippot, R.S. Fledman, \& E.J. Coats (Eds.), The social context of nonverbal behavior (pp. 71-108). Paris: Cambridge University Press.

Segrin, C. (2000). Social skill deficits associated with depression. Clinical Psychology Review, 20, 379-403.

Segrin, C., \& Abramson, L.Y. (1994). Negative reactions to depressive behaviors: A communication theories analysis. Journal of Abnormal Psychology, 103, 655668.
Sund, A.M., Larsson, B., \& Wichstrøm, L. (2003). Psychosocial correlates of depressive symptoms among 12-14-year-old Norwegian adolescents. Journal of Child Psychology and Psychiatry, 44, 588-597.

Underwood, M.K., Coie, J.D., \& Herbsman, C.R. (1992). Display rules for anger and aggression in school-age children. Child Development, 63, 366-380.

Wierzbicki, M., \& McCabe, M. (1988). Social skills and subsequent depressive symptomology in children. Journal of Clinical Child Psychology, 17, 203-208.

Zeman, J., \& Garber, J. (1996). Display rules for anger, sadness, and pain: It depends on who is watching. Child Development, 67, 957-973.

Manuscript accepted 27 April 2006 